\title{
Effects of dual task training on gait temporal-spatial parameters of children with autism
}

\author{
Felipe Heylan Nogueira de Souza', Ana Karoline Pordeus Lisboa², Maria De Fátima Targino Maia², \\ Mikaelle Rossane Duarte Dos Santos², Edson Meneses da Silva Filho', Leandro Gonçalves Cezarino', \\ Roberta de Oliveira Cacho', Ênio Walker Azevedo Cacho'
}

\begin{abstract}
Background: Autism Spectrum Disorder (ASD) is neurological conditions typically identified in early childhood. Children with ASD mainly suffer from incapacities in communication and social interaction, in addition to exhibiting unusual patterns of behavior. Objective: The present study aimed to evaluate the effects of the dual task training in the temporal-spatial aspects of gait in children with ASD. Method: It is a series of case which used as assessments the Childhood Autism Rating Scale (CARS), Motor Function Measurement, Tinetti Index and Plantigraphy. The incremental treadmill test was used previously to establish the appropriate velocity of each subject for the accomplishment of the double task protocol. Initially a warm-up of three minutes was done at three $\mathrm{km} / \mathrm{h}$, then increments of $1 \mathrm{~km} / \mathrm{h}$ were performed every three minutes and the maximum speed was obtained when the individual reached the speed limit of their ambulation. All subjects underwent an experimental protocol consisting of performing dual task activities on an Embreex $552^{\circledR}$ treadmill for four weeks, twice a week on alternate days and each activity lasted three minutes. Results: The sample consisted of 6 individuals. The pre- and post-test values for gait and balance, evaluated using the Tinetti Index, was 23.33 ( \pm 2.87 ) for the pre-test and $24.16( \pm 1.72)$ for the post-test with no statistical significance $(p=0.317)$. The types of foot of the sample were $50 \%$ flat feet, $25 \%$ high arches feet and $25 \%$ neutral feet. The axial and proximal motor function presented statistical difference in the intragroup analysis $(p=0.008)$. Conclusion: The protocol was not sufficient to verify improvements in the gait of children with autism.
\end{abstract}

Keywords: Autistic Disorder, Child, Rehabilitation

\section{INTRODUCTION}

The Autism Spectrum Disorders (ASD) are permanent neurological conditions typically identified in early childhood. The children with ASD suffer mainly deficiencies in communication and social interaction, and show unusual patterns of behavior ${ }^{(1)}$. Additional features of the ASD is the existence of abnormal movements and motor deficits which include irregular motor signs, impairment of postural control, instability, lack of coordination and changes in gait ${ }^{(2)}$.

Walking involves movements of the limbs in a repetitive sequence, while preserving stability and may be evaluated quantitatively for producing spatial, kinematic and kinetic parameters which may be used for the examination of any deviation from a pattern of normal walking ${ }^{(3)}$. The study of the gait has been a mastery of movement which attracted interest for several years in that population ${ }^{(4,5)}$.

Evidence in the literature ${ }^{(6)}$, demonstrate a wide range of movement disorders and gait deviations in individuals with ASD. The movement disorders which influenced the gait were observed during the age of development of children and young adolescents with ASD, including temporal and spatial changes and kinematic ${ }^{(3,4)}$.

In everyday life, children get used to undertake activities simultaneously when walking ${ }^{(5)}$ and it was evidenced that the decrease in the right parietal cortex may compromise the coding of synesthetic aspects of the movement, which consequently contributes to delayed motor development of these children, compromising the execution of double activities $^{(7)}$. That occur because of the existence of cognitive and motor interference between tasks, which will compete with each other for the same class capabilities in processing information in the central nervous system (CNS) $)^{(8,9)}$.

Studies have been pointed out that in double tasks conditions, the gait performance may be impaired while walking, resulting in a decrease of the temporal variable space ${ }^{(10)}$. In children, studies indicate that the dual task situations alter the walking performance, showing that the gait regulation is not a fully automatic activity, however it requires cognitive processes ${ }^{(11)}$. 
Children with ASD have deficits in executive tasks which require verbalization ${ }^{(12,13)}$, they present a smaller measures of attention, executive function ${ }^{(14,15)}$, language and frequently they engage in patterns of repetitive and stereotyped behaviors compared to children in typical development ${ }^{(2)}$.

Therefore, developing and testing the efficacy of motor interventions associated with cognition in children with ASD may contribute to the development of protocols which may improve their social, cognitive and motor interactions.

Thus, the present study aimed to evaluate the effects of the dual task training in the temporal-spatial aspects of gait in children with ASD.

\section{METHODS}

This is a descriptive study of case series, with pre-design testing - Post-tests. The assessment and intervention methods used in the present study followed the rules of Resolution No. 422/12 of the National Council on Health Research involving human subjects and it was approved by the Research Ethics Committee of the State University of Paraíba, under Protocol 1,712,774. After choosing the participants, the consent of the parents or guardians of the children selected for the study was requested through a Free and Informed Consent Term.

\section{SAMPLE}

The study enrolled subjects aged between 3 and 17 years, diagnosed with ASD, with scores below 37 points in the Childhood Autism Rating Scale (CARS) and who were accompanying the Association of Parents and Friends of Exceptional Children (APAE) in the city of Campina Grande - PB, Brazil. The study excluded individuals who showed Disorder Deficit attention with hyperactivity disorder (DDAHD), severe mental retardation and other associated pathology.

\section{PROCEDURES}

The evaluation of individuals was performed using an evaluation sheet containing the evaluated degree of autism data through CARS range, performance of motor function by measuring the motor function (MMF) and gait through the Tinetti index and Plantigraphy. The same evaluation was used before and after the period of application of the treatment protocol. The CARS consist of a rating scale widely used by researchers and clinicians to assist in the diagnosis of children with autism over two years, ranking the pathology: autism mild, moderate or severe, with 15 items covering social relationship, sensitive response (tactile, visual, auditory and olfactory), emotional response, verbal and nonverbal communication, adaptation and change, using of objects, intellectual response and movements of the body. The scores for each domain range from one to four with punctuation between 15 and $60^{(16)}$.
The modified MMF, in turn, is suitable for children from three to seven years old, in which consists of 20 steps and divided into 3 dimensions: D1 - standing and transfers; D2 - axial and proximal motor function; and D3 - distal motor function. Each of the 20 items graduated from zero to three points, with zero when it is not possible start the requested task and three when performing the activity normally ${ }^{(17)}$.

The Tinetti index is indicated in body balance and gait, composed of two scales, one of gait and another, balance. The instrument consists of multiple tasks which depend on the integration of physical, cognitive and psychological, for a total of 16 activities which are assessed through observation of the researcher. The full realization of the scales adds 28 points, and score lower than 19 indicates high risk of falls, 19-24 moderate risk of falls and from 24 to 28 low risk of falls. Thus, the lower the score is, the greater is the balance commitment and gait of the individual ${ }^{(18)}$.

The plantigraphy, used for gait evaluation, it consists of an examination which gives the impression of the soles of the subjects recorded on paper fixed to the ground. The participants had the soles painted with ink stamp and were instructed to walk over a $1.5 \mathrm{~m}$ paper, leaving the impression of the feet while walking. Through that examination it was possible to obtain the kind of foot, step size and step width ${ }^{(19)}$. For classification of feet types, Viladot method was used ${ }^{(20)}$. The speed was obtained by timing how long each participant took to walk a distance of six meters. To calculate the cadence the following formula was used:

$$
\text { Speed }(\mathrm{cm} / \mathrm{s})=\frac{\text { step length }(\mathrm{cm}) \times \text { cadency }(\text { steps } / \mathrm{min})}{120}
$$

\section{DATA COLLECTION}

The Incremental Tread Test was used previously to establish the appropriate velocity of each subject for the accomplishment of the double task protocol, in which after a warm-up time of three minutes at three $\mathrm{km} / \mathrm{h}$, it was incremented every three minutes $1 \mathrm{~km} / \mathrm{h}$, the maximum speed was reached when the individual has reached the limit speed of ambulation (21).

The subjects enrolled in the present study underwent an experimental protocol consisted of dual task of activities on a treadmill Embreex $552^{\circledR}$ (Embreex Ltd., Brusque, SC, Brazil) for four weeks twice a week on every other days, and each activity lasting three minutes. The protocol was composed by marching with motor demand: where the volunteer walked on the treadmill holding a tray with glasses; gait with cognitive demand: the volunteer walked on the treadmill while talking the color of the card that the researcher was holding in front of him, with cycles of changing every 20 seconds; and gait with motor and cognitive demand the participant walked on the treadmill while transferring $50 \mathrm{~mm}$ size styrofoam balls from a vest pocket to another while, simultaneously, spoke the 
color of the ball. Between each exercise, there was 5 minutes for rest.

\section{STATISTICAL ANALYSIS}

The data obtained in evaluations were calculated using descriptive statistics, which include minimum and maximum values, mean and standard deviation. To investigate the normality of the data, we used the Shapiro-Wilk test for all quantitative variables. In order to compare the pre- and post-treatment values, we used the Student test-t for paired samples of step, gait speed, cadence, obtained by Plantigraphy as well as for CARS, MMF and Tinetti. In order to observe the relationship between the dimensions of the MMF, the Pearson's correlation was used. In all analyzes, the statistical significance was $5 \%(p=0.05)$.

\section{RESULTS}

Initially 14 individuals were considered eligible to participate in the study, however 8 did not meet the inclusion criteria, remaining six participants in the sample. All process is shown in figure 1.

In the remaining six subjects of the sample, four (75\%) were female and two (25\%) were male, with a mean age of 5.16 (1.16) years. To perform the protocol the Incremental Treadmill Test was performed and the average speed of $4.25 \mathrm{~km} / \mathrm{h}$ ( 0.43 ) was established. To compare the pre- and post-test regarding gait and balance, assessed by the Index Tinetti, the average of 23.33 ( 2.87) for the two pre-tests and 4.16 (1.72) for post-test was obtained, noting that there was no statistically significant difference $(p=0.317)$.

Graph 1 shows the plantigraphy data, measured in centimeters. They were able to differentiate the types of walk from each participant through Viladot method, in which $50 \%$ of participants had flat foot, $25 \%$ cavus foot and $25 \%$ neutral foot.

The tables 1, 2 and 3 shows the comparison results between the pre- and post-test, with regard to the evaluation of participants through the MMF scale pre- and post-protocol, and no significant differences were observed.

\section{DISCUSSION}

The results of the present study, which aimed to investigate the effects on autistic patients motor performance through the application of a protocol with dual task of activities show that during the realization of the tasks which demanded talks the participants, despite having a restricted vocabulary, suppressed speech by performing only the motor part of the activity. When encouraged to speak, they felt the necessity to stop walking to respond.

In a study using dual task to assess the central executive performance in autism ${ }^{(22)}$, confirmed that the ASD individuals can not use the verbal ability during the performance of secondary tasks, stating that that happens due to a failure in the executive performance in cognitive domains.
The symptoms presented by ASD indicate impairment of the pre-frontal area of the brain which is responsible for executive function. Thus, the autistic person presents difficulty in dividing its attention between a motor activity and a cognitive activity. As García-Villamisar and Sala ${ }^{(23)}$ demonstrated through a study comparing a group of autistic adults with a group of healthy

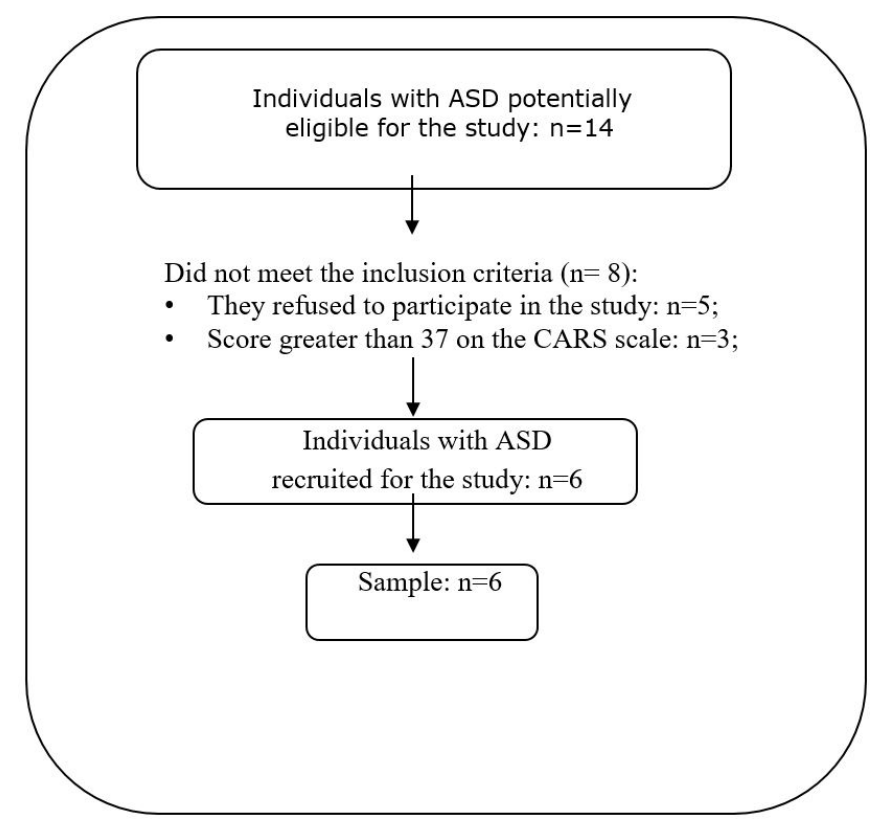

Figure 1. Eligibility flowchart of the subjects.

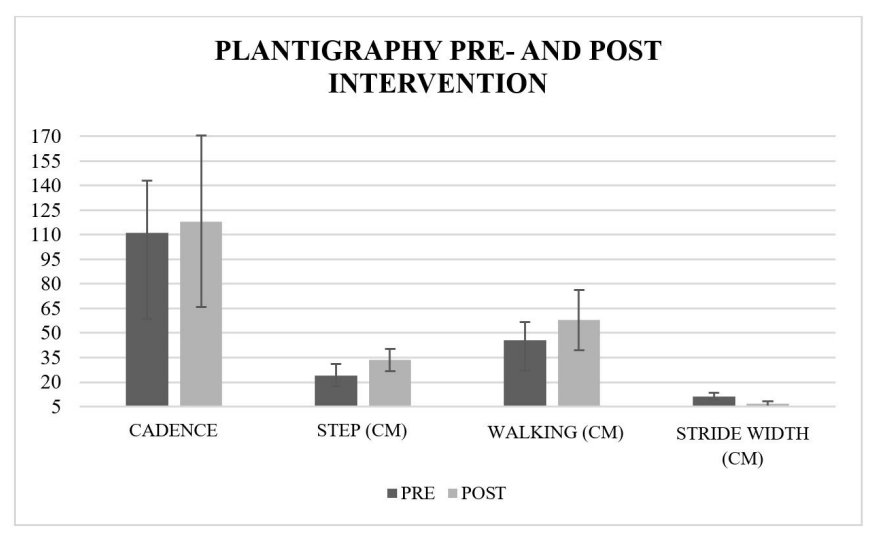

Graph 1. Plantigraphy pre- and post-gait training on the treadmill.

Table 1. Dimension 1: Stand up and transfer

\begin{tabular}{cccc}
\hline \multirow{2}{*}{ Variables } & \multicolumn{2}{c}{ Dimension $\mathbf{1}(\mathrm{n}=6)$} & P \\
\cline { 2 - 3 } & \multicolumn{2}{c}{ Before } & After \\
\hline Min-Max & $54.10-70.80$ & $62.50-83.30$ & 0.442 \\
Mean \pm SD & $62.45( \pm 5.89)$ & $6.67( \pm 4.74)$ & \\
\hline \multicolumn{4}{c}{ Confidence Interval } \\
Cl (95\%) & \multicolumn{2}{c}{-8.56 to 4.36} \\
\hline
\end{tabular}

Note: Descriptive analysis, through the Student $t$ test, the maximum and minimum values, mean and standard deviation of Motor Function Measure, before and after the dual task intervention. 
Table 2: Axial and proximal motor function

\begin{tabular}{cccc}
\hline \multirow{2}{*}{ Variables } & \multicolumn{2}{c}{ Dimension 2 ( $\mathbf{n}=6)$} \\
\cline { 2 - 3 } & \multicolumn{2}{c}{ Before } & After \\
\hline Min-Max & $54.10-70.80$ & $66.60-79.10$ & $0.008^{*}$ \\
Mean \pm SD & $62.45( \pm 5.89)$ & $70.77( \pm 4.74)$ & \\
\hline \multicolumn{4}{c}{ Confidence Interval } \\
Cl (95\%) & \multicolumn{2}{c}{-13.30 a -3.34} \\
\hline
\end{tabular}

Note: Descriptive analysis, through the Student $t$ test, the maximum and minimum values, mean and standard deviation of Motor Function Measure before and after the dual task of intervention.

Table 3: Distal Motor Function

\begin{tabular}{cccc}
\hline \multirow{2}{*}{ Variables } & \multicolumn{2}{c}{ Dimension $\mathbf{3}(\mathrm{n}=6)$} & \\
\cline { 2 - 3 } & \multicolumn{2}{c}{ Before } & After \\
\hline Min-Max & $33.30-91.60$ & $33.30-91.60$ \\
Mean \pm SD & $66.62( \pm 20.57)$ & $66.62( \pm 20.57)$ & 1.000 \\
\hline \multicolumn{4}{c}{ Confidence Interval } \\
Cl (95\%) & \multicolumn{3}{c}{-16.59 a -16.59} \\
\hline
\end{tabular}

Note: Descriptive analysis, through the Student $t$ test, the maximum and minimum values, mean and standard deviation of Motor Function Measure before and after the dual task of intervention.

adults before dual-task activities, where the result achieved was that the performance in the dual task of autism is impaired in relation to that of the control group.

That damage is also evidenced by Bucci et al. ${ }^{(24)}$ in an experimental study using a dual task activity protocol, which aimed to verify the effect of eye movements on postural stability in children with autism and children with proper development age. The group of autistic children compared to normal children had become more unstable in dual task conditions, demonstrating that autistic motor development behaves differently on this type of activity.

When applying the dual task activity in autistic patients, we observed a slight increase in the improvement of motor function, as was shown in Tables 1, 2 and 3. Machado(25) conducted a case study of autism using the dance therapy, a technique which stimulates the motor function associated with the perception of movements and social interaction, to assess motor function by MMF, the individual obtained an improvement in the axial and proximal traction and changes in the direction of the head, which are essential to achieve the desired movement.

The results obtained by the Tinetti Index showed that the participants presented a decrease in the risk of falls, even below the statistical significance it is possible to note that the means of gait and balance were influenced in their aspects. For Chiao Yi et al. ${ }^{(20)}$ the musculoskeletal disorders such as plantar arch changes, require a readjustment of the load distribution joints which are part of the kinetic chain, which can lead to engine damage. When observing the results, it is highlighted that $50 \%$ of the sample presented flat foot, which can influence gait.

By Analyzing the graph data 1 , it is seen that when comparing the results pre- and post-treatment, there was not statistical significance, and while checking an increase in the number of steps and stride length and decrease the width of the steps, there was no difference between groups. Studies have shown that children with ASD as well as ataxic patients, demonstrate difficulty in straight walking and variation between step length and duration. These conditions suggest primary motor disorder based on basal ganglia, resulting in an abnormal gait, irregularities in the speed and cadence ${ }^{(26)}$.

\section{CONCLUSION}

The protocol used in the present study was not enough to check improvement in the gait of children with autism, also we did not observed losses in time-space measures the gait, as observed in other studies. It is open the hypothesis that perhaps the protocol application duration and the sample size have been insufficient to meet the desired effects, and suggest new protocols to be performed in larger groups and a higher application duration and consistent with the therapy. Therefore, it is important that further studies be made in order to better understand the executive functioning children with ASD and their influences on the gait, so that new treatment strategies may be formulated for this type of audience.

\section{AUTHOR'S CONTRIBUTIONS}

All authors contributed equally in the preparation of the study design, reviewing the important intellectual content, as well as analysis and data interpretation. EMSF and FHNS critically reviewed and approved the final version for publication. All authors are considered responsible for all aspects of the work ensuring the accuracy and completeness of the information contained therein.

\section{CONFLICT OF INTEREST}

All authors declare no conflict of interest

\section{AUTHOR DETAILS}

2 Faculdade Maurício de Nassau (UNINASSAU), Campina Grande (PB), Brazil.

\section{REFERENCES}

1. Manicolo O, Alexander GROB, Hagmann-von PARX. Gait in children with attention-deficit hyperactivity disorder in a dual-task paradigm. Frontiers In Psychology. 2017;8(34).

2. Didehbani N, Allen T, Kandalaft M, Krawczyk D, Chapman S. Virtual reality social cognition training for children with high functioning autism. Computers in human behavior. 2016;62:703-11.

3. Hasan CZC, Jailani R, Md Tahir N, Ilias S. The analysis of three-dimensional ground reaction forces during gait in children with autism spectrum disorders. Research in developmental disabilities. 2016;66:55-63.

4. Calhoun M, Longworth M, Chester VL. Gait patterns in children with autism. Clinical Biomechanics. 2011;26(2):200-6.

5. Esposito G, Venuti P, Apicella F, Muratori F. Analysis of unsupported gait in toddlers with autism. Brain and development. 2011;33(5):367-73. 
6. Kindregan D, Gallagher L, Gormley J. Gait deviations in children with autism spectrum disorders: A review. Autism Research and Treatment. 2015;1-8.

7. Okuda PM, Misquiatti ARN, Capellini SA. Caracterização do perfil motor de escolares com transtorno autístico. Revista educação especial. 2010;23(38):443-54.

8. Maciel MA, Silva ACM, Cyrilloc FN, Suely Santosd, Torriani-Pasin C. Impact of dual task on parkinson's disease, stroke and ataxia patients' gait: a comparative analysis. Psicologia: reflexão e crítica. 2014;27(2):351-7.

9. Silva, M.E.M.; Assunção, L.S. Efeitos da fisioterapia utilizando a técnica de integração sensorial no tratamento de pacientes autistas. Instituto de Pesquisas Aplicadas e Desenvolvimento Educacional-IPADE. 2011:14(27).

10. Plummer-D’Amato $P$, Altmann LJ, Saracino D, Fox E, Behrman AL, Marsiske M. Interactions between cognitive tasks and gait after stroke: a dual task study. Gait \& Posture. 2008;27(4):683-8.

11. Hagmann-von Arx P, Manicolo O, Lemola S, Grob A. Walking in SchoolAged Children in a Dual-Task Paradigm Is Related to Age But Not to Cognition, Motor Behavior, Injuries, or Psychosocial Functioning. Frontiers In Psychology. 2016;7:352.

12. Hung YC, Meredith GS, Gill SV. Influence of dual task constraints during walking for children. Gait \& Posture. 2013;38(3):450-4.

13. Hannant P, Cassidy S, Tavassoli T, Mann F. Sensorimotor Difficulties Are Associated with the Severity of Autism Spectrum Conditions. Frontiers In Integrative Neuroscience. 2016;10:28.

14. Joseph RM, McGrath LM, Tager-Flusberg H. Executive dysfunction and its relation to language ability in verbal school-age children with autism. Developmental neuropsychology. 2005;27(3):361-78.

15. Sanders J, Johnson KA, Garavan H, Gill M, Gallagher L. A review of neuropsychological and neuroimaging research in autistic spectrum disorders: Attention, inhibition and cognitive flexibility. Research in autism spectrum disorders. 2008;2(1).
16. Cucolicchio S, Di Matteo J, Paicheco J, Gomes C, Simone MF, Assumpção Jr FB. Correlação entre as escalas CARS e ATA no diagnóstico de Autismo. Medicina de reabilitação. 2010;29(1):6-8.

17. Iwabe C, Miranda-Pfeilsticker BHM, Nucci A. Medida da função motora: versão da escala para o português e estudo de confiabilidade. Revista Brasileira de Fisioterapia. 2008;12(5):417-24.

18. Szydloski TP, Tomicki C, Zanini SCC, Leguisamo CP. Marcha e equilíbrio em idosos institucionalizados: avaliação pré e pós-exercícios físicos. Revista kairós gerontologia. 2015;18(2):327-38.

19. Bley AS, Ferraz G, Dias LV, Bacha IL. Confiabilidade entre plantigrafia e da linha de Feiss na avaliação do arco longitudinal medial do pé. ConScientiae saúde. 2011;10(3):508-13.

20. Chiao Yi L, Neves ALS, Areia M, Neves JMO, Souza TP, Caranti DA. Influência do índice de massa corporal no equilíbrio e na configuração plantar em obesos adultos. Revista brasileira de medicina do esporte. 2014;20(1).

21. Pinto ESM, Barbosa KC, Santo MP, Magno LD, Rocha RS, Rocha LS. Infuência da dupla tarefa na esteira ergométrica sobre a doença de Parkinson. Ciência em movimento. 2015;17(35):9-18.

22. Holland L, Low J. Do children with autism use inner speech and visuospatial resources for the service of executive control? Evidence from suppression in dual tasks. British journal of developmental psychology. 2010;28:36991.

23. García-Villamisar D, Della Sala S. Dual-task performance in adults with autism. Cognitive neuropsychiatry. 2002;7(1):63-74.

24. Bucci MP, Doyen C, Contenjean Y, Kaye K. The Effect of Performing a Dual Task on Postural Control in Children with Autism. ISRN Neuroscience. 2013

25. Machado LT. Dançaterapia no autismo: um estudo de caso. Fisioterapia e pesquisa. $2015 ; 22(2): 205-11$.

26. Chester VL, Calhoun M. Gait Symmetry in Children with Autism. Autism Research and Treatment. 2012. 